\title{
Prolonged coma and delayed peripheral neuropathy after ingestion of phenoxyà-
} cetic acid weedkillers

\author{
JOHN F. O'REILLY \\ M.A., M.R.C.P. \\ Norfolk and Norwich Hospital, Norwich
}

\begin{abstract}
Summary
A case of prolonged coma and delayed peripheral neuropathy is reported following self-poisoning with a widely available domestic weedkiller containing phenoxyacetic acids. Attention is drawn to the potential toxicity of these weedkillers which may be delayed in onset, and to the possibility of spontaneous recovery from neurological abnormalities which may be severe and prolonged or late in onset.
\end{abstract}

KEY WORDS: poisoning, glycolates, hydrocarbons.

\section{Introduction}

The phenoxyacetic acids, dichlorophenoxyacetic acid (2,4-D) and trichlorophenoxyacetic acid (2, 4, 5$\mathrm{T}$ ), are widely used as domestic weedkillers and have been considered relatively non-toxic. Fatal selfpoisoning is rare but there have been occasional reports of ataxia, muscle weakness, and peripheral neuropathy following accidental skin exposure (Berwick, 1970). I report a case of prolonged coma and late-onset peripheral neuropathy following ingestion of a weedkiller containing 2,4-D and 2,4,5-T in a hydrocarbon solvent.

\section{Case report}

A 61-year-old man presented $1 \mathrm{hr}$ after swallowing $100 \mathrm{ml}$ of a selective weedkiller containing $24 \mathrm{~g}$ of 2,4-D and 7.5 $\mathrm{g}$ of 2,4,5-T together with $25 \mathrm{ml}$ of the hydrocarbon solvent A260 (BP chemicals). Despite gastric lavage he became drowsy and within $6 \mathrm{hr}$ was responsive only to pain, with increased tone and brisk lower limb reflexes. During this time he became pyrexial $38^{\circ} \mathrm{C}$ and tachypnoeic with respiratory rate of 25 per min. Arterial blood gases showed hypoxaemia $\mathrm{PaO}_{2} 8.3$ and hypocapnia $\mathrm{PaCO}_{2} 3.58 \mathrm{kPa}$ with respiratory alkalosis, pH 7.52. Plasma, urea and electrolytes and transaminases were normal.

Present address: Department of Respiratory Medicine, Bristol Royal Infirmary, Bristol BS2 8HW.
Within $24 \mathrm{hr}$ he became unresponsive to pain, an although his temperature returned to normal, he. remained tachypnoeic, and deeply unconscious for days, with normal brain stem reflexes and hypeg reflexia of the lower limbs. During this period he wats treated with continuous oxygen to maintain normaj $\mathrm{PaO}_{2}$, and forced diuresis with intravenous $5 \%$ dex trose, isotonic saline and potassium. Urinary toxicoP ogy screening revealed no detectable narcotic drugs and he did not respond to naloxone. Chest radios graphs were repeatedly normal. He regained cont sciousness on the 5th day when respiratory rate ant arterial blood gases became normal, and was giso charged well 2 days later.

One month later he presented again with progês sive difficulty in walking for several days, and found to have marked bilateral weakness of tibialis anterior. Nerve conduction studies confirmed peripho eral neuropathy with gross delay in lateral peroneâ nerve conduction. Three months later he had made $\frac{O}{2}$ full spontaneous recovery.

\section{Discussion}

Despite the widespread availability of phenoxy acetic acid weedkillers, reports of toxicity from selfo: poisoning are uncommon. An LD50 of about $40 \overrightarrow{\mathrm{Q}}$. $\mathrm{mg} / \mathrm{kg}$ has been quoted (Dudley and Thapar, 1972 and is of the order taken by our patient $(510 \mathrm{mg} / \mathrm{kg})$ A few cases with fatal outcome have been reported and in one instance, prolonged unconsciousness which responded to forced alkaline diuresis wit increased renal clearance of 2,4-D (Prescott, Park and Darrien, 1979). Our patient developed previ ously noted features of phenoxyacetic acid poisoning including pyrexia, hyperventilation and hypoxaemia and which have been attributed to uncoupling of oxidative phosphorylation (Brodie, 1952). Althouge prolonged peripheral neuropathy has been describef following skin exposure (Berwick, 1970), our patiense demonstrates that this may be delayed in onset ando may recover spontaneously following oral ingestion 
The hydrocarbon solvent also ingested is unlikely to have contributed significantly to this man's prolonged deep coma. Although these solvents may produce transient narcosis by inhalation, and severe pneumonitis by aspiration, oral toxicity is low with an $\mathrm{LD}_{50}$ of $12.3 \mathrm{ml} / \mathrm{kg}$ (Hine and Zuidema, 1970).

Phenoxyacetic acid poisoning is surprisingly rare considering the widespread domestic usage of such weedkillers, but important in that full recovery from coma may be anticipated after several days, and possibly accelerated by forced alkaline diuresis.

\section{Acknowledgment}

I would like to thank Dr J. S. Pryor for permission to report this case.

\section{References}

BERWICK, P. (1970) 2,4-dichlorophenoxyacetic acid poisoning in man. Journal of the American Medical Association, 214, 1114.

BRODIE, T.M. (1952) Effect of certain plant growth substances on oxidative phosphorylation in rat liver mitochondria. Proceedings of the Society for Experimental Biology and Medicine, 80, 533.

DUDLEY, A.W. \& THAPAR, N.T. (1972) Fatal human ingestion of 2,4-D, a common herbicide. Archives of Pathology, 94, 270.

HINE, C.H. \& ZUIDEMA, H.H. (1970) The toxicological properties of hydrocarbon solvents. Industrial Medicine, 39, 39.

PRESCOTT, L.F., PARK, J. \& DARRIEN, I. (1979) Treatment of severe 2,4-D and Mecoprop intoxication with alkaline diuresis. British Journal of Clinical Pharmacology, 7, 111.

(Accepted 21 March 1983) 